\title{
Circle of Willis Collateral During Temporary Internal Carotid Artery Occlusion I: Observations From Digital Subtraction Angiography
}

\author{
Stephen P. Lownie, Ramiro Larrazabal, Maximilian K. Kole
}

\begin{abstract}
Introduction: Impaired collateral circulation can lead to stroke during carotid endarterectomy. Carotid stump pressure (CSP) is used as a surrogate measure of collateral flow. The objective was to determine whether anatomical features obtained from digital subtraction angiography correlate with CSP during temporary internal carotid artery occlusion. The second objective was to use these features in combination to predict CSP. Methods: Digital subtraction angiographies from 102 patients obtained before endarterectomy were reviewed for anatomical variables including: degree of ipsilateral and contralateral carotid artery stenosis; patency of the anterior communicating artery; presence of crossflow into ipsilateral middle cerebral artery branches; and size ( $<$ or $\geq 1 \mathrm{~mm}$ calibre) of the ipsilateral proximal anterior cerebral (A1), the contralateral A1, and the ipsilateral posterior communicating arteries. At surgery, systemic mean arterial pressure (MAP) and CSP were recorded. Multiple regression analysis was used to assess for anatomical features significantly associated with CSP. A "predicted CSP" equation was applied to 54 subsequent patients and correlated with measured CSP Results: Variables correlating with CSP included MAP ( $p=0.001)$; the presence of severe contralateral carotid stenosis $(\mathrm{p}=0.002)$; patency of the anterior communicating artery $(\mathrm{p}=0.013)$; and the size of the contralateral A1 segment $(\mathrm{p}=0.029)$. Angiographic cross-flow, ipsilateral A1 size, and ipsilateral posterior communicating artery size were not significant. Predicted CSP correlated significantly with measured CSP $\left(\mathrm{p}<0.0001 ; R^{2}=0.34\right)$. Conclusions: Anatomical features and systemic MAP are associated with carotid stump pressure during internal carotid artery occlusion and account for a significant amount of its variation.
\end{abstract}

RÉSUMÉ: Circulation collatérale dans le cercle artériel de Willis pendant une occlusion temporaire de la carotide interne. 1 : observations à l'angiographie numérique. Contexte: Pendant une endartérectomie carotidienne, une altération de la circulation collatérale peut donner lieu à un accident vasculaire cérébral. La pression dans le moignon carotidien (PMC) est utilisée comme mesure substitutive du flux collatéral. Le but de cette étude était de déterminer si les caractéristiques anatomiques obtenues à l'angiographie numérique correspondent à la PMC pendant une occlusion temporaire de la carotide interne. Le deuxième objectif était d'utiliser une combinaison de ces caractéristiques pour prédire la PMC. Méthodologie: Nous avons revu l'angiographie numérique obtenue chez 102 patients avant l'endartérectomie pour documenter les variables anatomiques dont le degré de sténose homolatéral et controlatéral de la carotide, la perméabilité de la communicante antérieure, la présence de flux transversal dans les branches de l'artère cérébrale moyenne homolatérale et la taille (calibre $<$ ou $\geq 1 \mathrm{~mm}$ ) de l'artère cérébrale antérieure proximale homolatérale (A1), de l'A1 controlatérale et des artères communicantes postérieures homolatérales. Au moment de la chirurgie, la pression artérielle moyenne systémique (PAM) et la PMC ont été enregistrées. L'analyse de régression multiple a été utilisée pour identifier les caractéristiques anatomiques associées de façon significative à la PMC. La « PAM prédite » a été calculée prospectivement au moyen d'une équation chez 54 patients consécutifs et corrélée à la PMC mesurée. Résultats: Les variables corrélées à la PMC étaient les suivantes : la PAM $(\mathrm{p}=0,001)$; la présence d'une sténose carotidienne controlatérale sévère $(\mathrm{p}=0,002)$; la perméabilité de l'artère communicante antérieure $(\mathrm{p}=0,013)$ et la taille du segment $\mathrm{A} 1$ controlatéral $(\mathrm{p}=0,029)$. Le flux angiographique transversal, la taille de l'A1 homolatérale et la taille de l'artère communicante postérieure homolatérale n'étaient pas des variables significatives au point de vue statistique. La PMC prédite était corrélée de façon significative à la PMC mesurée ( $<<0,0001 ; \mathrm{R} 2=0,34)$. Conclusions: Les caractéristiques anatomiques et la PAM systémique sont associées à la pression dans le moignon carotidien pendant l'occlusion de la carotide interne et expliquent une grande partie de sa variation.

Keywords: Carotid stenosis, carotid endarterectomy, carotid stump pressure, cerebral collateral circulation, circle of Willis doi:10.1017/cjn.2016.9

Can J Neurol Sci. 2016; 43: 533-537

Randomized clinical trials established that carotid endarterectomy (CEA) is beneficial in preventing stroke resulting from symptomatic severe carotid artery stenosis. ${ }^{1,2}$ However, a disabling stroke is also a potential complication of CEA. This may be due to either thromboembolic or hemodynamic events. The latter is related to insufficient collateral blood flow during

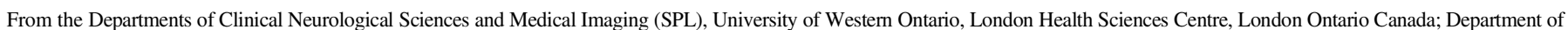
Radiology (RL), McMaster University, Hamilton Health Sciences, Hamilton Ontario Canada; Department of Neurosurgery (MKK), Henry Ford Health Sciences Center, Detroit, Michigan. ReCeived May 19, 2015. Final Revisions Submitted December 22, 2015.

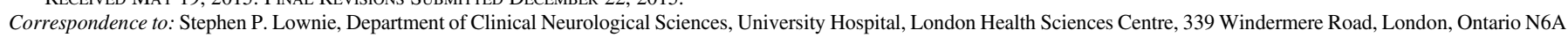
5A5. Email: steve.lownie@lhsc.on.ca 
temporary clamping of the carotid artery. Angiographic identification of collaterals assists in identifying CEA patients who are at lower risk of stroke. ${ }^{3}$ Such collaterals are associated with a five-fold lower risk of hemispheric stroke within 30 days of CEA. ${ }^{3}$

One measurement of the cerebral collateral circulation during surgery is the carotid artery stump pressure (CSP). ${ }^{4-6}$ This can predict cerebral hypoperfusion during CEA. CSP measurement is simple and compares favourably with other methods such as transcranial Doppler and somatosensory evoked potentials. ${ }^{7}$ Our study examined the preoperative digital subtraction angiograms of patients scheduled to undergo CEA to determine if any anatomical features correlated with intraoperative CSP values and whether they could predict critical hypoperfusion during carotid clamping. Predictive anatomical features could be of additional use in other situations involving spontaneous or deliberate carotid artery occlusion.

\section{MeTHODS}

Angiographic and hemodynamic data were collected according to the Canadian Tri-Council policy statement on ethical conduct for research involving the secondary use of data originally collected for health care purposes. One hundred and two consecutive patients (65 men, 37 women) between 45 and 86 years of age (mean, 69 years) were included. All had symptomatic severe internal carotid artery (ICA) stenosis of at least $70 \%$ according to North American Symptomatic Carotid Endarterectomy Trial criteria. ${ }^{1}$

During the period of data collection (late 1990s), all patients had routine preoperative selective angiography of the common carotid arteries and aortic arch and standard digital subtraction (DSA) or cut film images. At our institution, computed tomographic angiography (CTA) is the more contemporary diagnostic test performed before CEA, and results using that modality are the subject of our second report. DSA findings were reviewed before the CEA by a neuroradiologist (RL) blinded to the study question. The following were assessed: presence or absence of severe ( $>70 \%$ North American Symptomatic Carotid Endarterectomy Trial) stenosis of the ipsilateral and/or contralateral ICA; presence or absence of spontaneous cross-flow from the contralateral ICA into ipsilateral middle cerebral artery (MCA) branches; presence or absence of a patent anterior communicating artery as demonstrated by flow into both anterior cerebral artery A2 segments from either A1 segment; size of the ipsilateral and contralateral anterior cerebral artery A1 segments; and size of ipsilateral posterior communicating artery (PCoA). Vessel size was classified as $\geq 1 \mathrm{~mm}$ or $<1 \mathrm{~mm}$.

Carotid surgeries were performed after informed consent and under general endotracheal anaesthesia. The anesthesiologist routinely kept the partial pressure of carbon dioxide $>40 \mathrm{mmHg}$ immediately before and during carotid artery cross-clamping. Mean systemic pressure was obtained immediately before clamping. Upon clamping of the common carotid and external carotid arteries, CSP was measured using a 22-gauge needle placed in the common carotid artery just proximal to the carotid plaque and connected to a calibrated pressure transducer. ${ }^{6}$ CSP was allowed to stabilize for several seconds before measurement. Among the four surgeons who contributed data to the study, some never used shunts, whereas others used them only rarely. All agreed to measure CSP irrespective of whether or not they used shunts. Because this was an observational study to examine DSA imaging versus CSP, there was no intention to study surgical management or clinical outcome based on CSP.
Table 1: CSP: regression analysis of all variables

\begin{tabular}{l|c|l|c}
\hline Significant Variables & p Value & Nonsignificant Variables & p Value \\
\hline Systemic mean pressure & 0.001 & Ipsilateral A1 & 0.398 \\
\hline Contralateral stenosis & 0.002 & Ipsilateral Pcomm & 0.614 \\
\hline Anterior communicating & 0.013 & Ipsilateral stenosis & 0.326 \\
\hline Contralateral A1 & 0.029 & Angiographic cross-flow & 0.976 \\
\hline & & Age & 0.250 \\
\hline & & Gender & 0.461 \\
\hline
\end{tabular}

A1, anterior cerebral artery proximal to anterior communicating artery; CSP, carotid stump pressure; PCoA, posterior communicating artery.

Statistical analyses were performed by independent biostatisticians using the SAS System (the REG procedure). Multiple regression analysis using backward elimination was performed to select the features most strongly associated with CSP.

Based on the statistical analysis, a simplified regression equation was used to calculate a "predicted CSP." The equation was simplified so that the operating surgeon could quickly mentally calculate a predicted CSP based on the patient's systemic blood pressure and known anatomy immediately before clamping the carotid. In a subsequent operated consecutive series of 54 individuals, the simplified CSP was calculated and the actual CSP was again measured. Correlation coefficient, standard deviation (SD) of residuals, F-test, analysis of variance, and Runs test for linearity were performed. A residual plot was created to determine whether the residuals were normally distributed.

\section{Results}

Of the 10 hemodynamic and demographic variables evaluated, four were found to be significantly associated with CSP (Table 1). These included: systemic mean arterial pressure (MAP), the presence of severe contralateral stenosis (Con Sten), a patent anterior communicating artery (ACoA), and the size of the

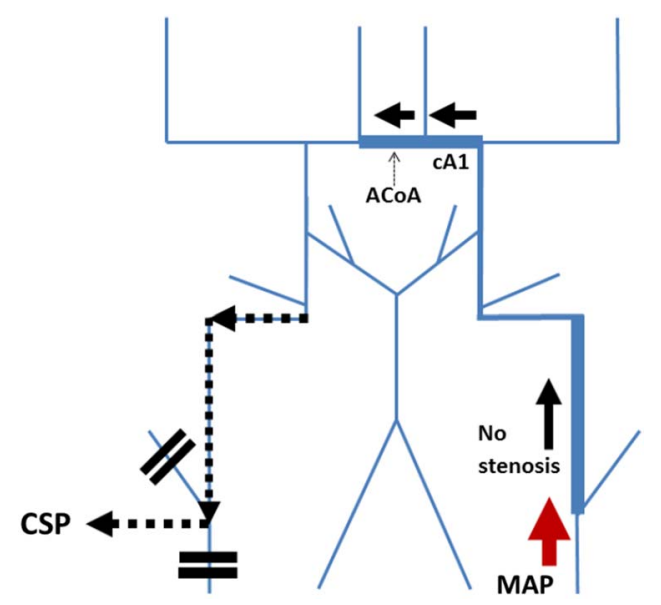

Figure 1: Vascular segments with statistically significant association with CSP in 102 patients using multiple regression analysis with backward elimination. ACoA, anterior communicating artery; cA1, contralateral A1; CSP, carotid stump pressure; MAP, mean arterial pressure. 
contralateral A1 segment (Con A1). These four factors explained $24 \%$ of the variability in CSP (Figure 1).

The simplified regression equation for "predicted CSP" equaled: 1/3 MAP - 10 (Con Sten $)+10($ ACoA $)+10$ (Con A1). The value of Con Sten was allocated as 1 or 0 , depending on the presence or absence of severe contralateral stenosis, respectively. ACoA was allocated as 1 if filling and 0 if not observed. Con A1 was allocated as 1 if the diameter of the contralateral $\mathrm{A} 1$ was $\geq 1 \mathrm{~mm}$, or 0 if its size was $<1 \mathrm{~mm}$. Predicted CSP demonstrated a significant correlation with actual CSP at the time of surgery in the 54 subsequently operated patients. Mean predicted CSP $( \pm$ SD) was $46.5 \pm 6.25 \mathrm{mmHg}$ (range, $33-60 \mathrm{mmHg}$ ) and mean actual CSP $( \pm \mathrm{SD})$ was $49.5 \pm 11.8 \mathrm{mmHg}$ (range, $30-78 \mathrm{mmHg}$ ). Correlation coefficient (r) was $0.5827 ; R^{2}$ was 0.3395 . The $\mathrm{SD}$ of residuals from line $(\mathrm{Sy}, \mathrm{x})$ was 9.743 . To test whether the slope was significantly different from zero, the $\mathrm{F}$ value was determined to be 26.732 , and the $\mathrm{p}$ value was $<0.0001$, considered extremely significant. From the analysis of variance, the linear regression (model) showed a sum of squares of 2537.5 and a mean square of 2537.5; deviations from linearity (residual) showed a sum of squares of 4936.0 and a mean square of 94.923 . Runs test demonstrated 23 points above the line, 31 below, and 33 runs. There was not a significant departure from linearity $(p=0.9577$, not significant) (Figure 2). Residuals, consisting of the differences between individual predicted stump pressures and actual measured stump pressures at surgery, are

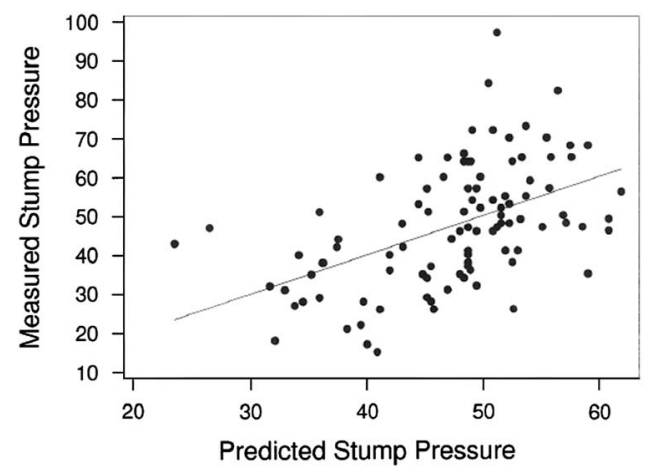

Figure 2: Validation of model in 54 subsequent patients. Predicted CSP demonstrates a significant correlation with actual CSP at the time of surgery $(p<0.0001, r$-squared $=0.34)$. plotted in Figure 3. The model appeared fairly normally distributed, with residuals within a range to be of surgical relevance.

\section{DiscuSsion}

Measurement of the carotid stump pressure is a simple widely used method to assess cerebral hemispheric collateral blood flow during carotid surgery and balloon test occlusion. It is used during CEA to decide whether temporary shunting of the clamped carotid might be required to prevent hemodynamic stroke. It has also been used to predict tolerance to therapeutic balloon occlusion of the carotid artery. ${ }^{8}$ In this study, the goal was to examine preoperative angiographic and hemodynamic factors to determine if there was any association with the level of CSP. In elucidating such factors, it might be possible to predict the tolerance to occlusion of the ICA using easily available radiological findings. Certain patients with $\mathrm{CSP}<25 \mathrm{mmHg}$ may be at increased risk of hemodynamic stroke during carotid cross-clamping. Surgeons who perform selective shunting will depend on individual CSP levels to make the shunt decision in the operating room. However, correlating preoperative neurovascular imaging with CSP could alert the surgeon preoperatively that shunting may be required.

\section{SMP}

This study confirms the dependence of the CSP on the systemic mean blood pressure. ${ }^{4-6}$ Moore found a statistically significant correlation between CSP and MAP in 36 patients. ${ }^{6}$ In 23 patients, Hays found that elevating systemic blood pressure usually elevated CSP by approximately $1 \mathrm{mmHg}$ for every $2 \mathrm{mmHg}$ rise in MAP. ${ }^{5}$ Baseline CSP influences the responsiveness to MAP: at baseline CSP levels lower than $40 \mathrm{mmHg}$, it is more difficult to elevate it, with as low as a 1:4 relationship. ${ }^{9}$

\section{Contralateral ICA}

The most important anatomic variable associated with CSP was the presence of severe contralateral stenosis or occlusion. In our study, the mean CSP was $49 \mathrm{mmHg}$ in cases with no contralateral stenosis, but $39 \mathrm{mmHg}$ in cases with $>70 \%$ contralateral stenosis (two-tailed t-test; $\mathrm{p}=0.0041$ ). The CSP is dependent on the patency of the contralateral ICA (Table 2). ${ }^{4,10,11}$ Sweet and Bennett $^{12}$ noted that temporary occlusion of the contralateral

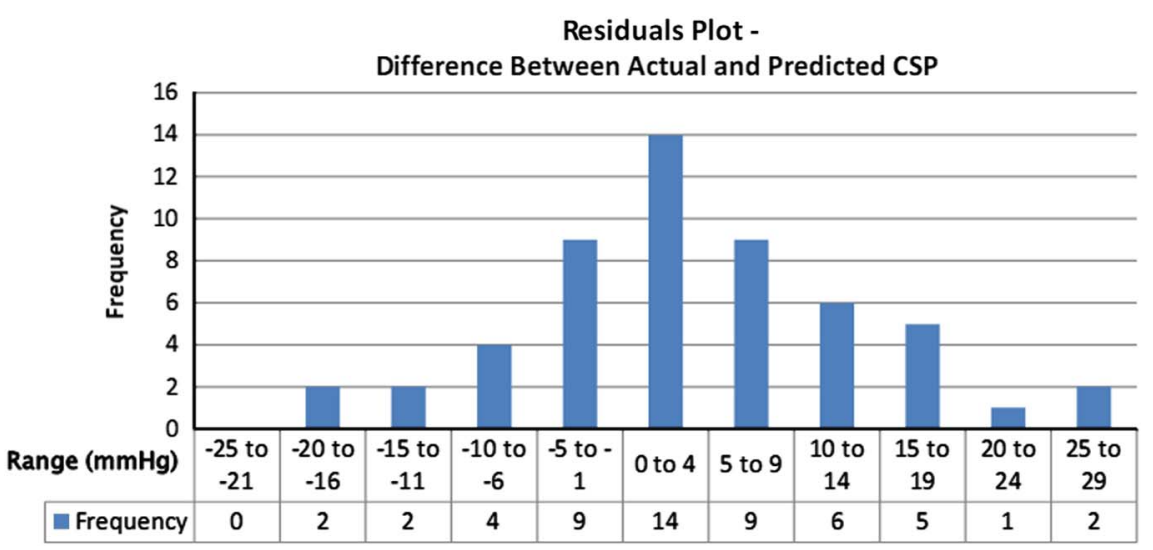

Figure 3: Plot of residual differences between predicted CSP and actual CSP in 54 patients. CSP, carotid stump pressure. 
Table 2: Mean CSP related to the status of contralateral internal carotid artery

\begin{tabular}{l|c|c|l}
\hline & & \multicolumn{2}{|c}{ Contralateral ICA } \\
\hline Author, Year & $\mathbf{n}$ & No Stenosis & Occluded or Stenosed \\
\hline Crawford, ${ }^{4} 1960$ & 17 & 63 & 25 (all occluded) \\
\hline Moore, ${ }^{11} 1973$ & 107 & 49 & 32 (all occluded) \\
\hline Harada, ${ }^{10} 1995$ & 140 & 53 & 41 (all occluded) \\
\hline Present study & 101 & 49 & 39 (stenosed) \\
\hline
\end{tabular}

ICA, internal carotid artery; CSP, carotid stump pressure.

carotid artery sometimes produces a marked drop in CSP. This may reflect the capacity of the PCoA to provide supply from the basilar when the carotids are occluded.

\section{Anterior Circle of Willis}

The patency of the anterior communicating artery and the diameter of the Con A1 proved to be significantly associated with CSP. These are two of the three anatomic components connecting the ICAs via the anterior Circle of Willis, which is regarded as the most important source of collateral blood supply to the brain. ${ }^{13,14}$ The significance of the ACoA and Con A1 is logical because these vessels convey flow to the ipsilateral hemiphere. ${ }^{15,16}$ Interestingly, angiographic cross-flow did not emerge as a significant predictor of collateral blood flow. This is contrary to other studies, ${ }^{13,17}$ but may be due to redundancy. The presence or absence of visible cross-flow apparently adds little to the level of collateral flow already explained by ACoA and the calibre of the Con A1. With ACoA flow present and with a Con A1 greater than $1 \mathrm{~mm}$, cross-flow may only become prominent when the ipsilateral carotid is nearly (>95\%) occluded. The calibre of the ipsilateral A1 also did not emerge as an important factor, an unexpected finding for an intrinsic component of the anterior Circle of Willis. However, even with a small ipsilateral A1, a large Con A1 still serves as an important source of flow to both A2 segments. The A2 may then be able to contribute to the distal MCA via leptomeningeal connections. In such situations, the ipsilateral MCA and its lenticulostriates may need to pull collateral flow from the posterior communicating and ophthalmic arteries. On the other hand, some degree of patency of the ipsilateral A1 would mitigate the rare and dangerous "isolated hemisphere."

\section{PCoA}

The calibre of the PCoA did not emerge as a significant factor. This contrasts with other studies. ${ }^{18-20}$ However, the PCoA is a less frequent source of collateral supply compared with the anterior Circle of Willis. Although the number of our cases is greater than 100, it may have been insufficient to demonstrate a relationship.

\section{Limitations of Study}

Our study has some limitations. Only the Circle of Willis collateral pathways were evaluated. Potentially important collateral supply exists from other sources including extracranial pathways and leptomeningeal connections. However, these sources do not usually contribute significant collateral flow during acute occlusion of the carotid artery. ${ }^{14,21}$ A second limitation concerns the use of DSA. Contemporary noninvasive imaging modalities such as CTA and magnetic resonance angiography could have improved the sensitivity and accuracy of the study. Investigation using CTA has been completed and is the subject of our second report. Results using DSA are still considered relevant in situations in which pretreatment DSA has been performed (e.g. in balloon test or therapeutic ICA occlusion). DSA results also serve as a useful reference to compare subsequent results using CTA. At our centre, these results have been found helpful in anticipating the need for selective shunting during CEA.

\section{Conclusion}

Intraoperative carotid stump pressure can be predicted with accuracy using the systemic mean arterial pressure and data from preoperative DSA. These provide an estimate of the adequacy of the collateral circulation. The prediction of the CSP may be useful during procedures involving temporary or permanent carotid occlusion, highlighting the potential for dangerously low collateral flow. It may also be useful in situations in which the carotid artery becomes occluded spontaneously in certain disease states.

\section{Disclosures}

The authors report no conflict of interest concerning the materials or methods used in this study or the findings specified in this paper.

\section{ACKNOWLEDGEMENTS}

The authors acknowledge the following colleagues: R. Sahjpaul, G.G. Ferguson, and H.W.K. Barr for contributing stump pressure data; M. Eliasziw and L. Stitt for performing statistical analyses; M. Bussiere, A. Leung, and D.M. Pelz for providing critical review of the manuscript.

\section{REFERENCES}

1. North American Symptomatic Carotid Endarterectomy Trial Collaborators. Beneficial effect of carotid endarterectomy in symptomatic patients with high-grade carotid stenosis. N Engl J Med. 1991;325:445-53.

2. European Carotid Surgery Trial Collaborators. Randomised trial of endarterectomy for recently symptomatic carotid stenosis: final results of the MRC European Carotid Surgery Trial (ECST). Lancet. 1998;351:1379-87.

3. Henderson RD, Eliasziw M, Fox AJ, et al. for the North American Symptomatic Carotid Endarterectomy Trial (NASCET) Group. Angiographically defined collateral circulation and risk of stroke in patients with severe carotid artery stenosis. Stroke. 2000; 31:128-32.

4. Crawford ES, De Bakey ME, Blaisdell FW, et al. Hemodynamic alterations in patients with cerebral arterial insufficiency before and after operation. Surgery. 1960;48:76-94.

5. Hays RJ, Levinson SA, Wylie EJ. Intraoperative measurement of carotid back pressure as a guide to operative management for carotid endarterectomy. Surgery. 1972;72:953-60.

6. Moore WS, Hall AD. Carotid artery back pressure: a test of cerebral tolerance to carotid occlusion. Arch Surg. 1969;99:702-10.

7. Moritz S, Kasprzak P, Arlt M, Taeger K, Metz C. Accuracy of cerebral monitoring in detecting cerebral ischemia during carotid endarterectomy - a comparison of transcranial Doppler sonography, near-infrared spectroscopy, stump pressure, and somatosensory evoked potentials. Anesthesiology. 2007; 107:563-9. 
8. Tomura N, Omachi K, Takahashi S, et al. Comparison of technetium Tc 99m hexamethylpropyleneamine oxime single-photon emission tomograph with stump pressure during the balloon occlusion test of the internal carotid artery. AJNR Am J Neuroradiol. 2005;26:1937-42.

9. Boysen G. Cerebral perfusion pressure and collateral resistance during carotid clamping. Cerebral hemodynamics in carotid surgery. Acta Neurologica Scand Suppl. 1973;49:52-8.

10. Harada RN, Comerota AJ, Good GM, Hashemi HA, Hulihan JF. Stump pressure, electroencephalographic changes, and the contralateral carotid artery: another look at selective shunting. Am J Surg. 1995; 170:148-53.

11. Moore WS, Yee JM, Hall AD. Collateral cerebral blood pressure: an index of tolerance to temporary carotid occlusion. Arch Surg. 1973;106:520-3.

12. Sweet WH, Bennett HS. Changes in internal carotid pressure during carotid and jugular occlusion and their clinical significance. J Neurosurg. 1948;5:178-95.

13. Lopez-Bresnahan MV, Kearse LA, Yanez P, Young TI. Anterior communicating artery collateral flow protection against ischemic change during carotid endarterectomy. J Neurosurg. 1993; 79:379-82.
14. Mount LA, Taveras JM. Arteriographic demonstration of the collateral circulation of the cerebral hemispheres. Arch Neurol Psychiatry. 1957;78:235-53.

15. Dukes HT, Odom GL, Woodhall B. The unilateral anterior cerebral circulation. J Neurosurg. 1965;22:40-6.

16. Jawad K, Miller JD, Wyper DJ, Rowan JO. Measurement of CBF and carotid artery pressure compared with cerebral angiography in assessing collateral blood supply after carotid ligation. J Neurosurg. 1977;46:185-96.

17. Wilkinson HA, Wright RL, Sweet WH. Correlation of reduction in pressure and angiographic cross-filling with tolerance of carotid occlusion. J Neurosurg. 1965;22:241-5.

18. Alders BJ, Berry RG. Circle of Willis in anatomical disorders. Arch Neurol. 1963;8:398-402.

19. Battacharji SK, Hutchinson EC, McCall AJ. The circle of Willis: the incidence of developmental abnormalities in normal and infracted brains. Brain. 1967;90:747-58.

20. Schomer DF, Marks MP, Steinberg GK, et al. The anatomy of the posterior communicating artery as a risk factor for ischemic cerebral infarction. N Engl J Med. 1994;330:1565-70.

21. Pitts FW. Variations of collateral circulation in internal carotid occlusion: comparison of clinical and x-ray findings. Neurology. 1962;12:467-71. 